\title{
1940 NM FİBER LAZER KAYNAĞININ KARACİĞER DOKUSUNDAKİ ISIL HASARININ YAPAY SINIIR AĞLARI İLE TAHMINI
}

Öz: Bu çalışmada Yapay Sinir Ağları (YSA) yöntemi kullanılarak $1940 \mathrm{~nm}$ dalgaboyuna sahip lazer kaynağının karaciğer dokusu üzerinde oluşturduğu ısıl hasarların güç ve uygulama süreleri ile arasındaki ilişkisi incelenmiştir. Farklı güç değerlerine sahip lazer kaynağı koagülasyon ve karbonizasyon gözlenene kadar dokuya farklı sürelerde uygulanmıştır. Buna bağlı olarak radyal ve düşey yönde oluşan ısıl hasarlar deneysel olarak ölçülmüş ve kayıt altına alınmıştır. Bu kayıtların \%70'i Matlab ortamında geliştirilen YSA modellerini eğitmek için kullanılmıştır. Lazer gücü ve uygulama süreleri model için giriş verileri, koagülasyon/karbonizasyon oluşma durumu ve oluşan isıl hasarlar ise (çap, derinlik) modelin çıkış değerleri olarak kabul edilmiştir. Giriş verileri kullanılarak beş farklı öğrenme (LM, GDA, GDX, CGP ve BFG) algoritmasının en küçük kareler değeri (MSE) hesaplanmıştır ve karşılaştırılmıştır. Gizli katmanında 14 tane nörona sahip GDX, 2-14-3 yapısı, en iyi MSE (7,58E-2) sonucunu vermiştir ve eğitimde kullanılmayan veriler ile bu algoritmanın tahmin etme performansını test etmek için kullanılmıştır. Geliştirilen modelin ne kadar iyi çalıştığını anlamak için YSA tarafından tahmin edilen sonuçlar, deneysel sonuçlar ile karşılaştırılmıştır. Minimum \%2,7 ve \% 3,6 hata oranı ile dokuda oluşan 1sıl çap ve derinliklerinin tahmin edilebileceği gösterilmiştir. Bu sonuçlara göre, medikal uygulamalarda YSA yönteminin lazere yardımcı bir araç olarak kullanılması, çevre dokuların korunarak istenilen hedef bölgenin daha kontrollü ve daha yüksek doğrulukla tedavisini mümkün kılabilir.

Anahtar Kelimeler: Yapay Sinir Ağları (YSA), Makina Öğrenmesi, Koagülasyon, Karbonizasyon

\section{Prediction of 1940 nm Fiber Laser Induced Thermal Damage Using Artificial Neural Networks}

\begin{abstract}
These study presents relation between power and application time of $1940 \mathrm{~nm}$ laser source and thermal damage occurred on liver tissue using artificial neural networks (ANNs) method. Laser source with different powers and application times implemented on liver tissue until onset of coagulation and carbonization. Thermal damages occurred in horizontal and vertical direction have been experimentally measured and recorded. $70 \%$ of this data was used to training ANN model, which was built in Matlab environment. Power and application time were defined as input parameters of model. Coagulation /carbonization occurrence, diameter and depth of thermal damages were used as output of model. This data was used to calculate and compare MSE value of five different learning algorithm (LM, GDA, GDX, CGP ve BFG). GDX algorithm with a 14 neuron in hidden layer, 2-14-3, was resulted in minimum MSE value $(7.58 \mathrm{E}-2)$ and remaining untrained data was used to show prediction performance of GDX algorithm. ANN model outputs were compared with experimental results. It was shown that diameter and depth of coagulation and carbonization can be predicted using using ANN method with a minimum 2.7\% and $3.6 \%$ success rate, respectively. According to these results, ANN assisted laser thermal therapies can provide more accurate treatment of undesired target tissue (tumor) with a minimal damage of surrounding healthy tissues.
\end{abstract}

\footnotetext{
* Hakkari Üniversitesi, Mühendislik Fakültesi Elektrik-Elektronik Mühendisliği Bölümü, Hakkari

İletişim yazarı: Fikret Yıldız (fikretyildiz@ hakkari.edu.tr)
} 
Keywords: Artificial Neural Network (ANN), Machine Learning, Coagulation, Carbonization

\section{GíRiş}

Yapay sinir ağları (YSA) bilgisayar tabanlı karar verici akıllı makine öğrenme tekniklerindendir. Bilim, teknoloji ve endüstride yaygın bir şekilde kullanılmaktadır ( Fast ve Palmé, 2010; Jiang ve diğ., 2010; Kumar ve diğ.,2013; Huang ve di ̌̆g.,2007; Carleo ve Troyer, 2016; Amato ve diğ., 2013) ve farklı uygulama alanlarına sahiptir (Özdemir,2016). Hava durumu, finansal tahminlerinde (Shukur ve Lee, 2015; Tkáč ve Verner, 2015), tarım alanında (Cubero ve diğ., 2011), tekstil endüstrisi (Hung ve diğ., 2014; Hung ve diğ., 2011) ve malzeme mühendisliğindeki uygulamaları (Der Jan ve diğ.,2005) bunların bazılarıdır

Medikal uygulamalara bakıldığında ise doktorların daha doğru ve kesin teşhis ve tanı yapmalarına yardımcı bir araç olarak kullanılabileceği üzerine çalışmalar devam etmektedir. Yapay sinir ağ1 veya hibrit sinir ağları, hasta hakkında arşivlenen bilgilerin değerlendirilerek ileriki evrelerdeki hastalık durumu hakkında karar verilmesini (teşhis koyma) kolaylaştırma potansiyeline sahiptir (Søreide ve diğ., 2014; Seera ve Lim, 2014). Şeker hastalarının (C. Wang ve diğ., 2013), kalp hastalıklarının (Özdemir ve Danişman, 2011; Özdemir ve Danişman, 2015) göz hastalıklarının (Faust ve diğ., 2012), göğüs hastalıklarının teşhisi (Er ve diğ., 2010), MRI (Magnetic Resonance Imaging) görüntülerinin sınıflandırılması (Zhang ve diğ., 2011) ve diğer birçok farklı alandaki çalışmalar (Dursun ve diğ.,2017; Yucelbaş ve diğ.,2016;Yücelbaş ve diğ.,2016) YSA'nın tıp alanındaki uygulamalarına örnek olarak verilebilir.

Teşhis uygulamalarına ek olarak, tedavi amaçlı radyofrekans ve ultrason kaynakları kullanılarak dokuda oluşan 1sıl lezyonların boyut analizinde kullanılan YSA modellerinden literatürde bahsedilmişken (Rangraz ve diğ., 2012;Wang ve diğ., 2018), lazer kaynaklı 1 sıl zararların YSA modeli ile tahmin edilmesi ile ilgili literatürde sınırlı sayıda çalışma mevcuttur. $\mathrm{Bu}$ çalışmaların birinde, lazerin doku ablasyonu (dokunun kaldırılması) işlemi sırasında dokudaki 1sı dağılımı benzetimi (simüle) yapılmıştır. Benzetim sonuçları ile YSA tarafından tahmin edilen sonuçlar karşılaştırılarak hasar katsayısı hesaplanmıştır (Rao ve diğ., 2012). Buna benzer olarak diğer bir çalışmada ise lazer uygulama süresi ve lazer güç değerleri YSA modelinde giriş olarak kabul edilerek ablasyon zararı çap ve derinlik olarak tahmin edilmiştir (Su ve diğ., 2015). Son olarak farklı güçlere sahip 3 farklı lazer kaynağının in vitro ortamda (cansız) karaciğer dokusunda oluşturduğu koagülasyon çap ve derinlik değerlerinin tahmini YSA kullanılarak yapılmıştır ( Yildiz ve Özdemir, 2019).

Organın veya dokunun tamamen alınması veya doku nakline uygun olmayan tümörlerin tedavisi için az ağrılı, tekrarlanabilir ve düşük ölüm oranına sahip minimal girişimsel yöntemlere ihtiyaç duyulmaktadır. Dokuiçi lazer isıl tedavisi (LITT, Laser Interstitial Thermal Therapy) en yaygın kullanılan minimal girişimsel yöntemlerden biridir (Dick ve diğ., 2002). Dokuiçi lazer isıl tedavisinde, lazer enerjisi ince fiberler yardımıyla derinlerde bulunan dokulara taşınır ve hedef dokunun (tümörün) 1sitılarak ortadan kaldırılması amaçlanır ( Vogl ve diğ., 2001). Karaciğer, lenf dügümmlerinden sonra metastasların (anormal doku büyümesi) yayılımının en sık gözlemlendiği ikinci organ olmasından dolayı minimal girişimler sıkça uygulanmaktadır ( Vogl ve diğ., 2006). Genel olarak lazerin dokuda oluşturduğu 1sıl etkilerin üç farklı etkileşim mekanizmasının sonucu olduğundan bahsedilebilir. Bunlar sırasıyla, koagülasyon $\left(60^{\circ} \mathrm{C}\right)$, dokuda bulunan suyun buharlaşmasi/ ablasyon $\left(100 \quad{ }^{\circ} \mathrm{C}\right)$ ve bunu takiben oluşan karbonizasyondur (>100 ${ }^{\circ} \mathrm{C}$ dokunun yanması/siyah renge dönüşmesi) (Niemz, 2007) (Şekil 1).

Dokuda oluşan 1sıl hasarlar birbirini takiben hızlı bir şekilde meydana geldiğinden ve lazer ısıl tedavilerinin asıl amacı hedef tümörün ortadan kaldırılıp etraftaki sağlıklı dokuların en az zarar görmesi olduğundan, lazer kaynaklarının tedavi sırasında kontrollü bir şekilde kullanılması elzemdir. Örneğin lazer ile tedavi sırasında dokunun yanması -karbonize olması, ameliyat sırasında doktorun görüş açısını azalttığı için istenmeyen bir durumdur (Niemz,2007). Lazerin dokudaki isıl etkilerini (koagülasyon, karbonizasyon, ablasyon (doku kaldırılması)) gözlemlemek için yapılan akademik çalışmalarda genel olarak lazerin çıkış gücü ve uygulama 
zamanı manuel olarak değiştirilmektedir (Yildiz, 2012; Yildiz ve diğ., 2016). Dokuda oluşan hasara göre uygulama parametreleri (güç, süre) değiştirilmektedir. Doku ile kuvvetli etkileşime giren lazer

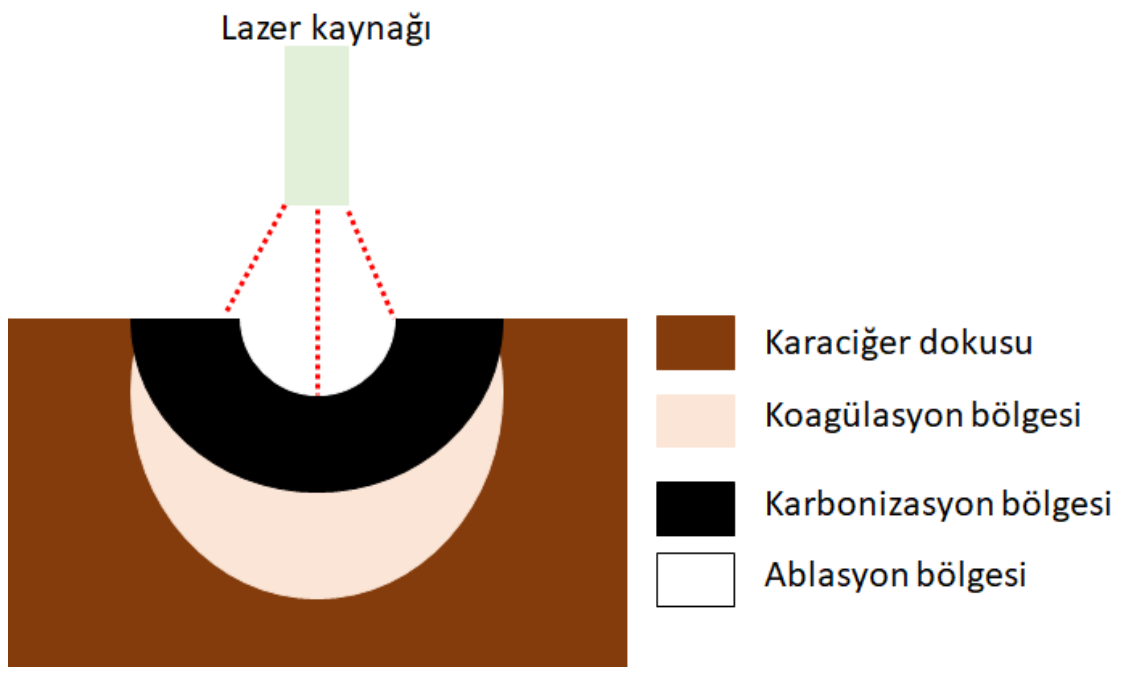

Şekil 1:

Lazer uygulanmasına göre dokuda oluşan koagülasyon, karbonizasyon ve ablasyon olayları

dalgaboyları düşünüldüğünde bu konu daha da önemli hale gelmektedir. Örneğin, $1940 \mathrm{~nm}$ dalga boyu doku ile hızlı etkileşime girdiğinden dolayı koagülasyon ile karbonizasyon olayları arasındaki geçişleri gözlemlemek ve kontrol etmek manuel olarak kolay değildir. YSA tabanlı otomatik akıllı sistemler, lazerlerle yapılan medikal operasyon sırasında oluşabilecek doku hasarı tahmin edilerek sağlıklı dokuların hasarı minimize edilebilir. Bu nedenlerden dolayı, lazer ile yapılan minimal girişimsel tümör tedavilerinin YSA ile gerçekleştirilmesi, hem doktor hem hastalar için daha kolay ve daha güvenli tedavi sağlayabilir.

$\mathrm{Bu}$ çalışmada, YSA tabanlı bir tahmin modeli geliştirilerek $1940 \mathrm{~nm}$ lazer kaynağının karaciğer dokusunda oluşturduğu 1sıl hasarın lazer güç değerine ve uygulama süresine göre tahmin edilmeye çalışılmıştır. Lazer güç değerleri ve uygulama süresi YSA modeli için giriş kabul edilerek radyal (yatay) ve dikey yönde dokuda oluşan 1sıl hasarın çap ve derinlik değerleri ve dokunun koagülasyon veya karbonize olup olmadığı tespit edilmiştir. Deneysel veriler ile YSA çıtılıarı karşılaştırılmış ve YSA yöntemi kullanılarak lazer kaynaklı ısıl hasarların tespiti hakkında sonuçlar tartışılmıştır.

\section{MATERYAL VE YÖNTEM}

\subsection{Verilerin Toplanması ve Model Geliştirme}

Bu çalışmada genellikle ablasyon (doku kaldırılması) uygulamaları için uygun olan 1940 nm dalgaboyuna sahip fiber laser kaynağı kullanılmıştır (Theisen-Kunde ve diğ.,2009). Deneysel veriler, lazer kaynağı cansız karaciğer dokusu üzerine $1 \mathrm{~cm}$ mesafeden koagülasyon (lazer uygulanan bölgenin çevresine göre soluklaşması) ve karbonizasyon (lazer uygulanan bölgenin çevresine göre siyahlaşması) gözlenene kadar uygulanmasıyla elde edilmiştir. Her ölçüm öncesi lazerin çıkış gücü kontrol edilmiştir ve daha sonra uygulanmıştır. $1940 \mathrm{~nm}$ dalgaboylu lazer maksimum $3 \mathrm{~W}$ değerine kadar çıkış verebildiği için ölçümler sadece 1,2 ve $3 \mathrm{~W}$ güç değerlerinde alınmıştır. İlk olarak lazer dokuya farklı güç değerlerinde uygulanarak koagülasyon ve karbonizasyon zamanları ölçülmüş̧ür. Her güç değeri için 10 adet ölçüm alınmıştır. Daha sonra deneysel olarak bu zaman aralığında ve güç değerinde dokuda radyal ve dikey yönde oluşan koagülasyon ve karbonizasyon çap ve derinlikleri ölçülmüştür. Sonuç 
olarak toplamda 60 tane veri elde edilmiştir. Bu çalışmada kullanılan deneysel veriler daha önceki çalışmalarda gösterilmiştir ve ölçümlerle ilgili detaylı bilgi bu çalışmalarda verilmiştir (Yildiz, 2012; Yildiz ve diğ., 2016; Yildiz ve Özdemir, 2019).

YSA, lazer güç değeri ve uygulama surelerini giriş verisi olarak kullanılarak bir model üretmek ve bu model ile çıkış değişkenlerinin (koagülasyon ve karbonizasyon çap, derinlik ve dokunun koagüle/karbonize olması durumu ) üretilmesini amaçlamaktadır. Şekil 2'de oluşturulan YSA modeli gösterilmektedir. Böylelikle hangi güç değerinin, hangi uygulama süresinde, dokuda nasıl bir ısıl hasar oluşturduğunun tespiti amaçlanmaktadır. Bu çalışmada çok tabakalı YSA modeli kullanılmıştır; model iki adet giriş, 1 adet gizli katman ve 1 adet çıkış katmanından ibarettir. YSA modellerinin başarısı kullanılan öğrenme algoritmasına ve gizli katmandaki nöron sayısına göre değişmektedir bu yüzden akademik çalışmalarda çok sayıda öğrenme algoritması kullanılmaktadır. Bu çalışma da öncelikle öğrenme algoritmalarının optimize edilmesi ve daha sonrada uygun bulunan algoritmanın tahmin etme başarısı değerlendirilmiştir. Bu çalışmada kullanılan öğrenme algoritmaları: LM (Levenberg-Marquardt backpropagation), GDA (Gradient descent with adaptive learning rate backpropagation), GDX (Gradient descent with momentum and adaptive learning rate backpropagation), CGP (Conjugate gradient backpropagation with Polak/Ribiére restarts) ve BFG (Quasi-Newton backpropagation)' dir. Bu algoritmalarla ilgili geniş bilgi literatürdeki birçok çalışmada verilmiştir (Cömert ve Kocamaz, 2017; Yildiz ve Özdemir, 2019).

$\mathrm{Bu}$ algoritmalar için, veriler arasındaki hatayi gösteren en küçük kareler (MSE, Minimum Square Error) değeri hesaplanmış ve MSE değerleri karşılaştırılarak gizli katmandaki en uygun nöron sayısı tespit edilmiştir. Bunun için YSA modelinde 2 değişken, yani lazer güç değeri ve lazer uygulama süreleri model için giriş parametreleri olarak kabul edilmiştir. Giriş katmanı 2 adet nörondan, çıkış katmanı ise 3 adet nörondan oluşmaktadır. Gizli katmandaki nöron sayısı da 2 ile 20 arasında değiştirilmiştir. Modelin çıkışında 3 farklı değer üretilmektedir; bunlar çap, derinlik ve dokunun koagülasyon/karbonizasyon olma durumudur.

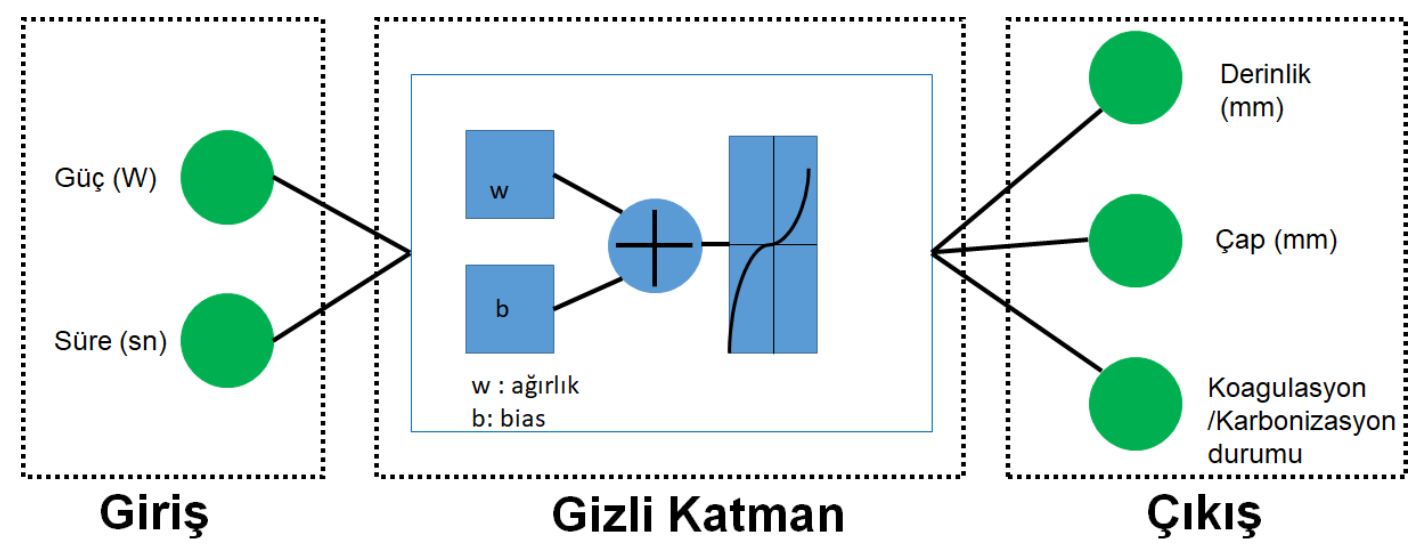

Sekil 2:

Çap, derinlik ve koagülasyon/karbonizasyon oluşma durumunun tahmini için kullanılan YSA modelinin yaplst

Gizli katmanda ve çıkış nöronlarında sigmoid aktivasyon fonksiyonu kullanılmıştır. A $\breve{g}$ eğitiminde kullanılan parametreler Tablo 1' de özetlenmiştir. Giriş ve çıkış verileri 0-1 arasında normalize edilmiştir. Koagülasyon ' 0 ' olarak karbonizasyon ise ' 1 ' olarak tanımlanmıştır. Toplam 60 deneysel veri sayıs eğitim $(\% 70)$ ve tahmin ( \%30) olmak üzere iki gruba ayrılmıştır. Dolayısıyla 60 veri arasından 42 tanesi ağın eğitiminde ve geri kalan 18 veride geliştirilen YSA modelinin tahmin etme gücünün test edilmesinde kullanılmıştır. Ağın eğitiminde iterasyon sayısı 1000 ve hedef 1E-5 olarak seçilmiştir. Maksimum iterasyona 
ulaşıldığında veya istenilen hedefe ulaşıldığında ağın eğitimi sonlandırılmıştır. Bu çalışmada kullanılan YSA modelinin iş akış diyagramı Şekil 3 ’te özetlenmiştir.

Tablo 1. YSA ağ eğitim parametreleri

\begin{tabular}{|l|l|}
\hline \multicolumn{1}{|c|}{ Parametreler } & \multicolumn{1}{c|}{ Özellikler } \\
\hline Giriş nöron sayısı & 2 \\
\hline Gizli katmandaki nöron sayısı & $2-20$ \\
\hline Çıkış nöron sayısı & 3 \\
\hline Eğitim fonksiyonları & LM, GDA, GDAX, CGP,BFG \\
\hline Performans fonksiyonu & En küçük Kareler Yöntemi (MSE) \\
\hline Aktivasyon fonksiyonu & Log-sigmoid \\
\hline Maksimum iterasyon & 1000 \\
\hline Hedef & $1 \mathrm{E}-05$ \\
\hline Öğrenme oranı & 0.01 \\
\hline Normalization & 0 veya 1 \\
\hline
\end{tabular}

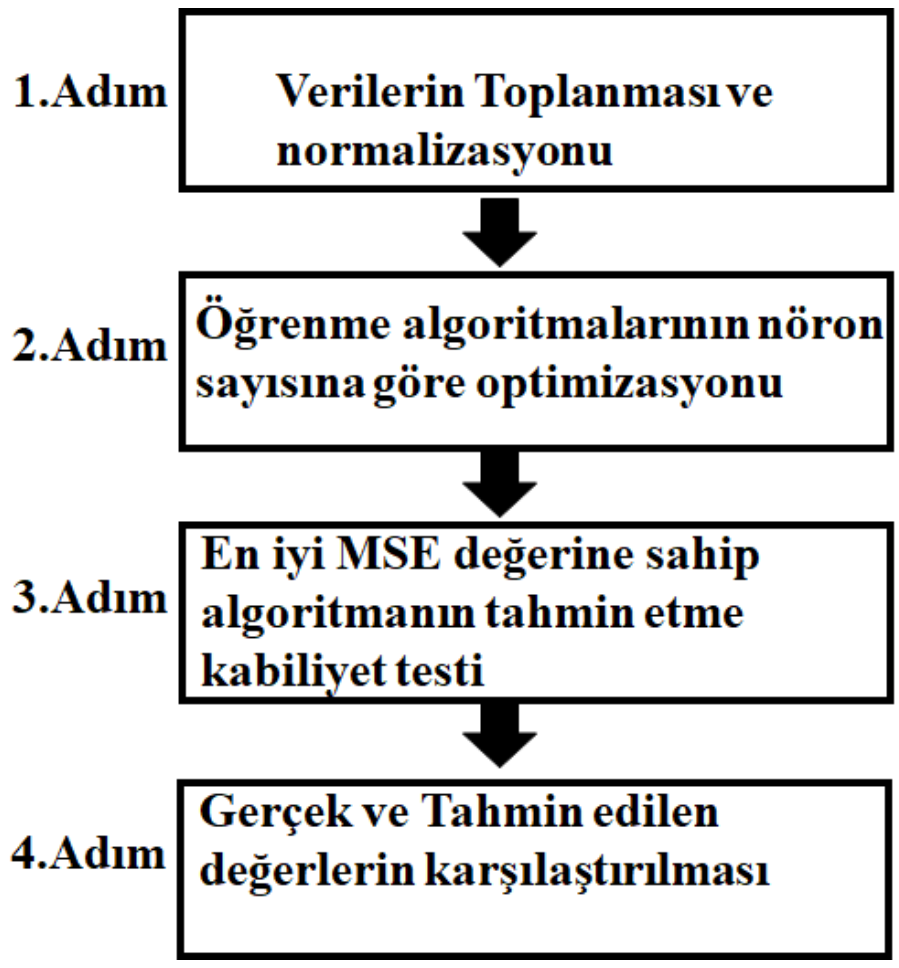

Şekil 3:

Kullanılan YSA modeli için iş akış diyagramı

\section{BULGULAR VE TARTIŞMA}

Tablo 2’ de 5 farklı öğrenme algoritmalarının gizli katmandaki nöron sayısına göre MSE değerlendirilmesi gösterilmiştir. YSA ile oluşturulan modelde algoritmaların MSE değerlerine bakıldığında, gizli katmanında 14 tane nöron bulunan GDX algoritması en duşük MSE değerine sahiptir (7,58E-2). En kötü performansıda 1,37E-1 MSE değeri ile 16 nörona sahip BFG algoritması göstermiştir. GDX algoritması için Tablo 2'den anlaşıldığı gibi nöron sayısı artışı ile MSE değeri düşmektedir dolayısıyla tahmin etme potansiyeli artmaktadır. Ancak gizli katmandaki nöron sayısının 14 değerinden daha fazla arttırılması MSE değerinin daha düşük değerlere inmesine sebep olmaktadır. Gizli katmanında 14 tane nöron bulunan GDX 
algoritmasından oluşan YSA modeli (2-14-3) en yüksek performansa sahip olmasından dolayı 1sıl hasar tahmini için optimum (en başarıl1) YSA modeli olarak kullanılmıştır. 2-14-3 yapısına sahip YSA modelinin tahmin etme gücü, ağın eğitiminde kullanılmayan 18 tane veri ile test edilmiştir. Deneysel veriler ile tahmin edilen veriler Şekil 4 ve Şekil 5' te beraber gösterilmiştir. Çap ve derinlik değerleri için tahmin edilen ile gerçek değerler arasındaki minimum yüzde fark sırasıyla \% 2,7 ve \%3,6 olarak hesaplanmıştır. Bu değerler $3 \mathrm{~W}$ laser gücü uygulandığında elde eldilen verilerden elde edilmiştir. Maksimum yüzde hata ise sırasıyla çap ve derinlik için \% 42 ve \% 73 olarak hesaplanmıştır. Çap değerinin tahmininde oluşan bu hata $1 \mathrm{~W}$ laser gücünün deneysel sonucunda olmasına rağmen derinlik değerinde oluşan maksimum hata $3 \mathrm{~W}$ laser gücünün deneysel sonuçları arasındadır. Şekil 6' te koagülasyon/karbonizasyon durumuna bakıldığında ise kogulasyon "0" olarak tanımlandığı için gerçek (deneysel) koagülasyon durumları şekilde gözükmemektedir. Çap ve derinlik değerleri ile karşılaştırıldığında, gerçek ve tahmini koagülasyon/karbonizasyon durumları arasındaki fark daha düşüktür. Giriş bölümünde bahsedildiği gibi laser kaynaklı doku hasarının YSA ile tahmini ile ilgili kısıtlı sayıda calışma bulunmaktadır. Bu calışmada az sayıda deneysel veri kullanılmasına rağmen, elde edilen sonuçlar göz önüne alındığında YSA ile 1sıl hasar tahmini potansiyel bir araç olabilir. Deneysel veri sayısının daha fazla kullanılması elde edilen sonuçlara pozitif etki edeceğinden, bu çalışmanın sonuçları gelecek çalışmalara yardımcı bir kaynak yada referans olabilir.

Tablo 2. Farkı Öğrenme algoritmalarının nöron sayısına göre MSE değerinin değişimi

\begin{tabular}{|l|l|l|l|l|l|}
\hline \multirow{2}{*}{$\begin{array}{c}\text { Gizli } \\
\text { Kämandaki }\end{array}$} & \multicolumn{5}{|c|}{ Algoritma } \\
\cline { 2 - 6 } & LM & \multicolumn{5}{|c|}{} & \\
& & GDA & GDX & CGP & BFG \\
\hline 2 & $7,83 \mathrm{E}-2$ & $8,56 \mathrm{E}-2$ & $9,00 \mathrm{E}-2$ & $1,00 \mathrm{E}-1$ & $1,10 \mathrm{E}-1$ \\
\hline 4 & $8,16 \mathrm{E}-2$ & $8,29 \mathrm{E}-2$ & $1,17 \mathrm{E}-1$ & $1,28 \mathrm{E}-1$ & $1,05 \mathrm{E}-1$ \\
\hline 6 & $7,68 \mathrm{E}-2$ & $1,14 \mathrm{E}-1$ & $8,66 \mathrm{E}-2$ & $1,24 \mathrm{E}-1$ & $1,23 \mathrm{E}-1$ \\
\hline 8 & $8,23 \mathrm{E}-2$ & $9,20 \mathrm{E}-2$ & $8,61 \mathrm{E}-2$ & $8,78 \mathrm{E}-2$ & $1,29 \mathrm{E}-1$ \\
\hline 10 & $7,79 \mathrm{E}-2$ & $7,61 \mathrm{E}-2$ & $9,08 \mathrm{E}-2$ & $8,08 \mathrm{E}-2$ & $8,19 \mathrm{E}-2$ \\
\hline 12 & $7,73 \mathrm{E}-2$ & $1,00 \mathrm{E}-2$ & $1,44 \mathrm{E}-1$ & $1,18 \mathrm{E}-1$ & $1,28 \mathrm{E}-1$ \\
\hline $\mathbf{1 4}$ & $7,65 \mathrm{E}-2$ & $1,11 \mathrm{E}-1$ & $7,58 \mathrm{E}-2$ & $7,89 \mathrm{E}-2$ & $1,28 \mathrm{E}-1$ \\
\hline 16 & $7,63 \mathrm{E}-2$ & $8,38 \mathrm{E}-2$ & $1,23 \mathrm{E}-1$ & $7,75 \mathrm{E}-2$ & $1,37 \mathrm{E}-1$ \\
\hline 18 & $7,70 \mathrm{E}-2$ & $7,94 \mathrm{E}-2$ & $8,17 \mathrm{E}-2$ & $8,23 \mathrm{E}-2$ & $1,35 \mathrm{E}-1$ \\
\hline 20 & $7,83 \mathrm{E}-2$ & $9,02 \mathrm{E}-2$ & $8,49 \mathrm{E}-2$ & $8,50 \mathrm{E}-2$ & $1,22 \mathrm{E}-1$ \\
\hline
\end{tabular}

Lazerin gücü ve uygulama sürelerinin 1sıl hasarlarla arasındaki ilişkini belirlemek için eğitim verileri kullanılarak 2-14-3 yapısına sahip YSA modelinin regresyon analizi de yapılmıştır (Şekil 7). Regresyon analizinde kullanılan veriler sırasıyla eğitim, test ve doğrulama için rastgele olarak sirasıyla \%70, \%15 ve \%15 olarak bölünmüştür. Eğitim, doğrulama ve test verileri için regresyon değerleri $(\mathrm{R})$ sırasıyla $0,9381,0,92709$ ve 0,92224 olarak hesaplanmıştır. 
Başka bir ifadeyle, minimum regresyon \% 92'in üzerinde elde edilmiştir. Bu regresyon analiz sonuçları lazerin uygulama zamanı ve güç değeri ile dokuda oluşan ısıl hasarlar ile arasında güçlü bir ilişki olduğunu göstermektedir.

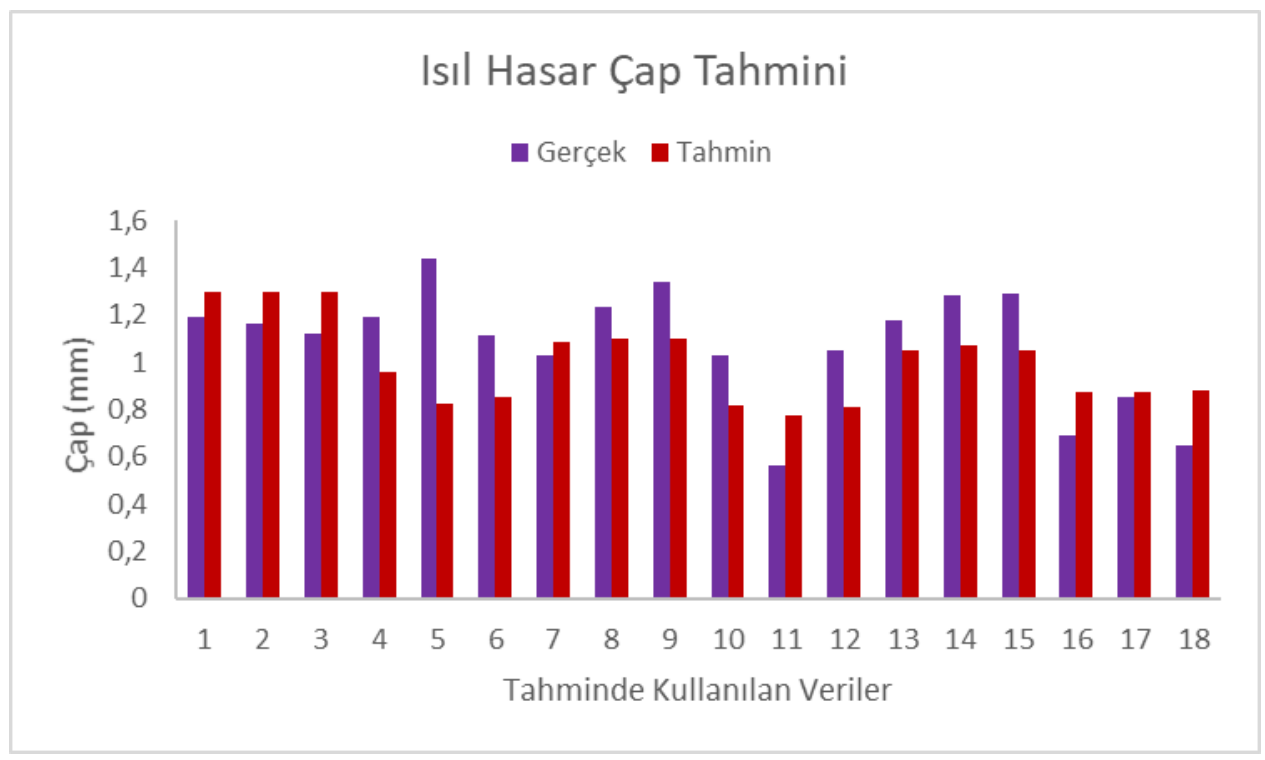

Şekil 4:

Isıl çapın gerçek ve tahmin edilen değerlerinin karşılaştırılması

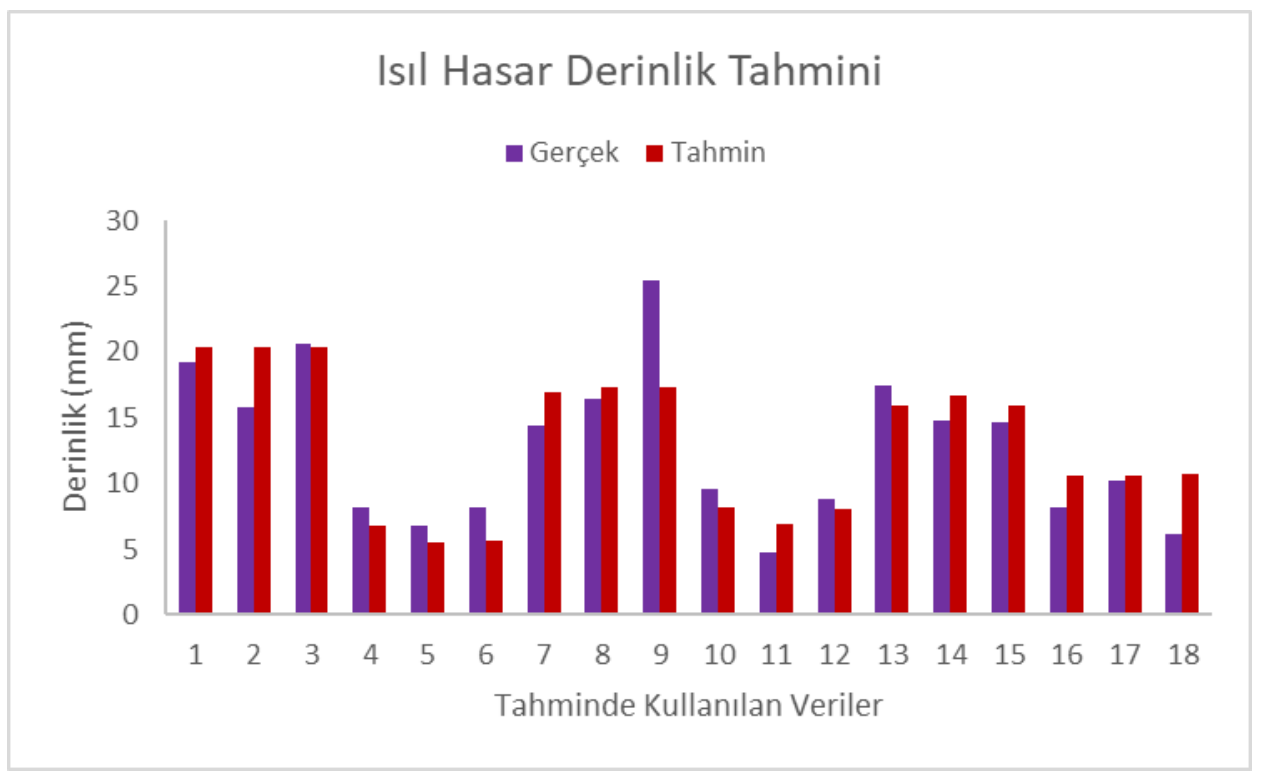

Şekil 5:

Isıl derinliğin gerçek ve tahmin edilen değerlerinin karşılaştırılması 


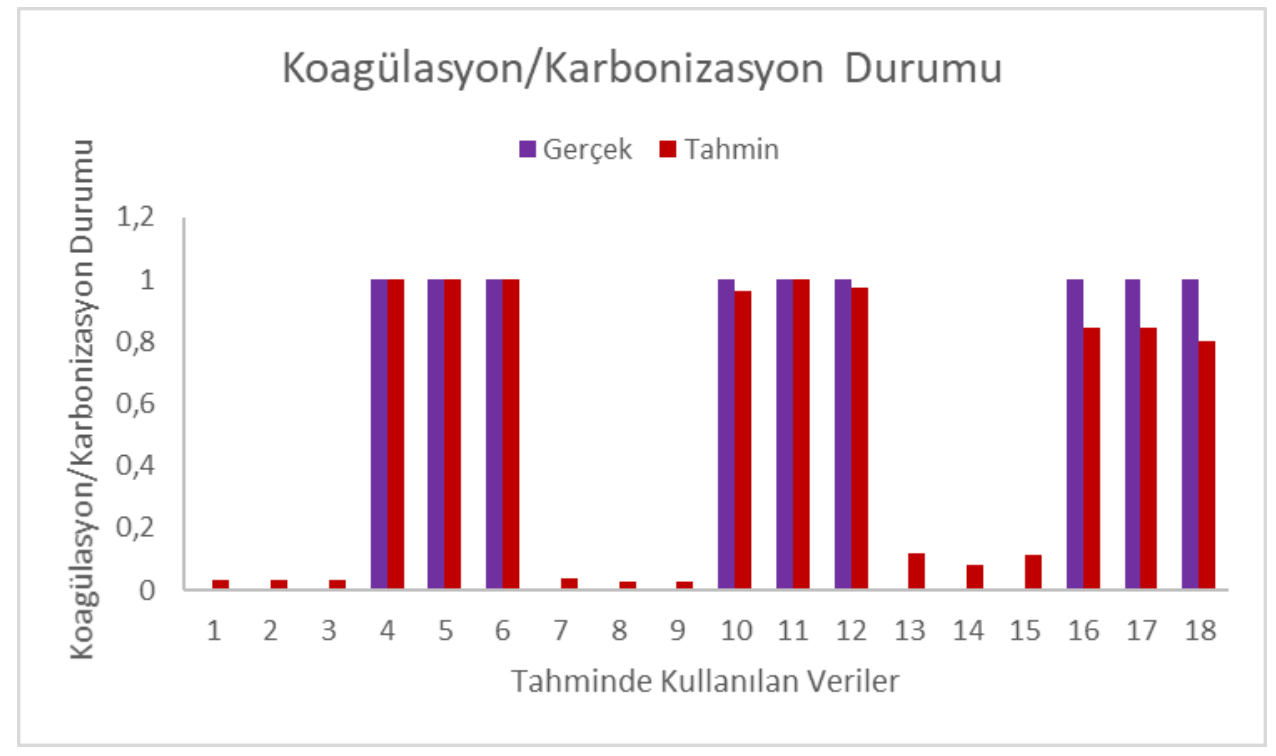

Şekil 6:

Koagülasyon/Karbonizasyon durumunun gerçek ve tahmini $n$ edilen değerlerinin karşılaştırılması
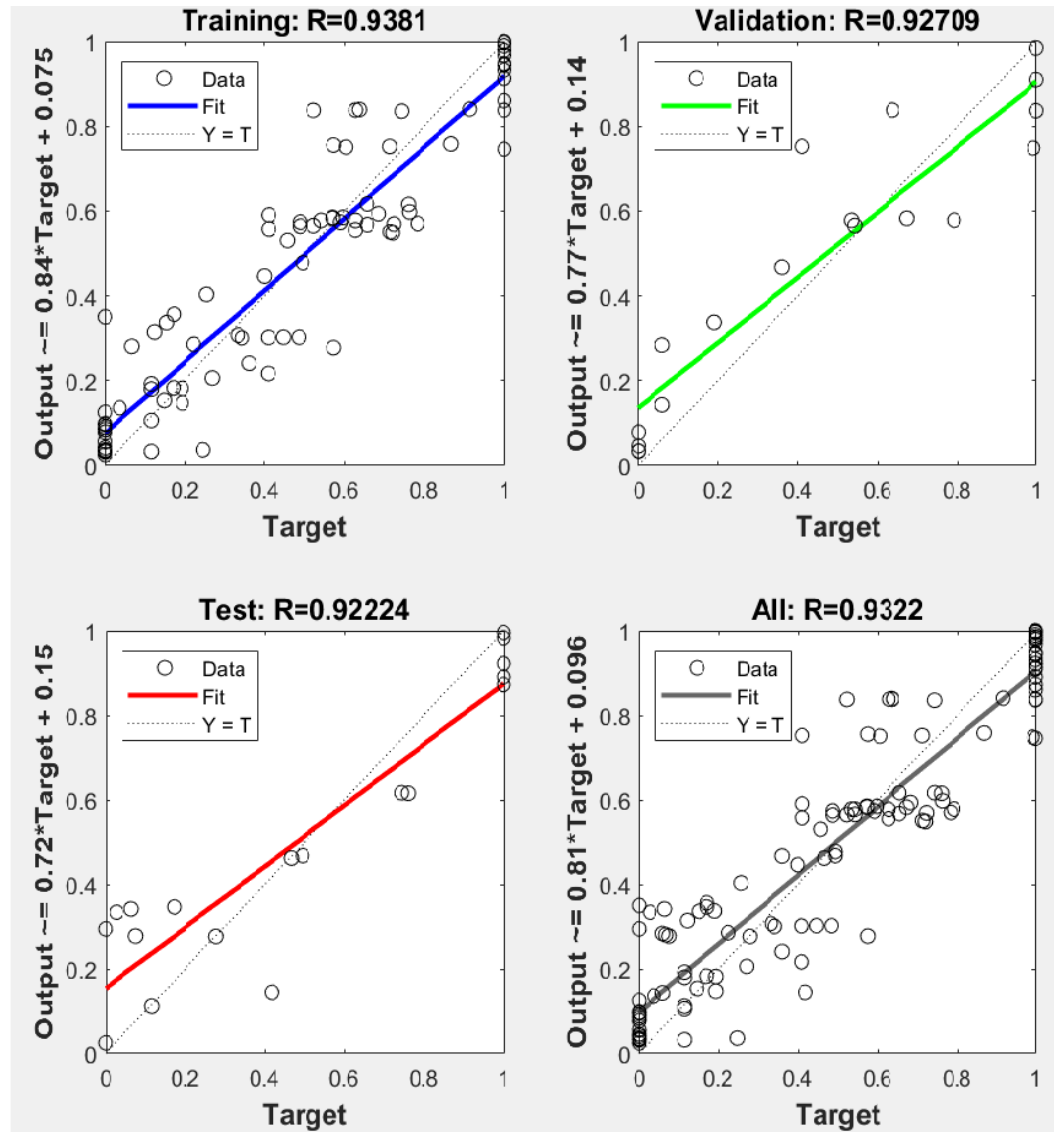

Şekil 7:

Regresyon analiz sonuçları (Training: Eğitim, Validation: Doğrulama, Test: Test ve All: Genel) 


\section{SONUÇLAR}

Bu çalışmada YSA yönteminin 1940 nm fiber lazerin dokuda oluşturduğu 1s1l etkilerin tahmini/analizlerinde kullanılabilirliği test edilmiştir. In vitro ortamda karaciğer dokusunda oluşan isıl hasarların tespiti için oluşturulan 2-14-3 yapısındaki YSA modelinin test sonuçları incelendiğinde, GDX algoritması kullanılarak minimum \% 2,7 ve \% 3,6 hata oran1 ile dokudaki 1sıl hasarın çap ve derinliğine karar verilebilir. Dolayısıyla az sayıdaki deneysel veri sayısına rağmen edilen sonuçlar gelecek çalışmalar için umut vericidir. Gelecek çalışmalarda veri sayısı arttırılarak YSA'nın performansı değerlendirilebilir. Özetle, YSA yönteminin lazerlere yardımcı araç olarak kullanılması, dokuda oluşacak 1sıl hasarın önceden tahmin edilerek doktorun operasyonu bu bilgiler altında gerçekleştirmesi daha doğru ve zararsız tedavi yöntemlerine imkân sağlayabilir. Bu sayede özellikle yaşlı hastalar için daha güvenilir bir tedavi ortamı sağlanmış olur.

\section{KAYNAKLAR}

1. Amato, F., López, A., Peña-Méndez, E. M., Vaňhara, P., Hampl, A. and Havel, J. (2013) Artificial neural networks in medical diagnosis, Journal of Applied Biomedicine, 11(2),4758. doi:10.2478/v10136-012-0031-x

2. Carleo, G. and Troyer, M. (2016) Solving the Quantum Many-Body Problem with Artificial Neural Networks, arXiv e-prints, 127383. doi:10.1126/science.aag2302

3. Cömert, Z. and Kocamaz, A. (2017) A Study of Artificial Neural Network Training Algorithms for Classification of Cardiotocography Signals, Bitlis Eren University Journal of Science and Technology, 7(2),93-103. doi:10.17678/beuscitech.338085

4. Cubero, S., Aleixos, N., Moltó, E., Gómez-Sanchis, J. and Blasco, J. (2011) Advances in Machine Vision Applications for Automatic Inspection and Quality Evaluation of Fruits and Vegetables, Food and Bioprocess Technology, 4(4),487-504. doi:10.1007/s11947-0100411-8

5. Dick, E. A., Taylor-Robinson, S. D., Thomas, H. C. and Gedroyc, W. M. W. (2002) Ablative therapy for liver tumours, Gut, 50(5), 733-739. doi:10.1136/gut.50.5.733

6. Dursun, M., Özşen, S., Yücelbaş, C., Yücelbaş, Ş., Tezel, G., Küççüktürk, S. and Yosunkaya, Ş. (2017) A new approach to eliminating EOG artifacts from the sleep EEG signals for the automatic sleep stage classification,Neural Computing and Applications, 28(10), 3095-3112. doi: 10.1007/s00521-016-2578-z

7. Er, O., Yumusak, N. and Temurtas, F. (2010) Chest diseases diagnosis using artificial neural networks, Expert Systems with Applications, 37(12), 7648 - 7655. doi:10.1016/j.eswa.2010.04.078

8. Fast, M. and Palmé, T. (2010) Application of artificial neural networks to the condition monitoring and diagnosis of a combined heat and power plant, Energy, 35(2),1114-1120. doi:10.1016/j.energy.2009.06.005

9. Faust, O., Acharya U., R., Ng, E. Y. K., Ng, K.-H. and Suri, J. S. (2012) Algorithms for the Automated Detection of Diabetic Retinopathy Using Digital Fundus Images: A Review, Journal of Medical Systems, 36(1), 145-157. doi:10.1007/s10916-010-9454-7

10. Huang, Y., Kangas, L. J., Rasco, B. A. (2007) Applications of Artificial Neural Networks (ANNs) in food science, Critical Reviews in Food Science and Nutrition, 47(2), 113-126. doi:10.1080/10408390600626453 
11. Hung, O. N., Chan, C. K., Kan, C. W., Yuen, C. W. M. and Song, L. J. (2014) Artificial neural network approach for predicting colour properties of laser-treated denim fabrics, Fibers and Polymers, 15(6), 1330-1336. doi:10.1007/s12221-014-1330-5

12. Hung, O. N., Song, L. J., Chan, C. K., Kan, C. W. and Yuen, C. W. M. (2011) Using artificial neural network to predict colour properties of laser-treated $100 \%$ cotton fabric, Fibers and Polymers, 12(8), 1069-1076. doi:10.1007/s12221-011-1069-1

13. Jean, M.D., Liu, C. D. and Wang, J. T. (2005) Design and development of artificial neural networks for depositing powders in coating treatment, Applied Surface Science, 245(1-4), 290-303. doi:10.1016/j.apsusc.2004.10.041

14. Jiang, J., Trundle, P. and Ren, J. (2010) Medical image analysis with artificial neural networks, Computerized Medical Imaging and Graphics, 34(8), 617-631. doi:10.1016/j.compmedimag.2010.07.003

15. Kumar, K., Parida, M. and Katiyar, V. K. (2013) Short Term Traffic Flow Prediction for a Non Urban Highway Using Artificial Neural Network, Procedia - Social and Behavioral Sciences, 104, 755-764. doi:10.1016/j.sbspro.2013.11.170

16. Niemz, M. H. (2007) Lasers-Tissue Interactions: Fundamentals and Applications, Springer. doi:10.1007/978-3-662-04717-0

17. Özdemir, A. T. and Danisman, K. (2015) A comparative study of two different FPGA-based arrhythmia classifier architectures, Turkish Journal of Electrical Engineering and Computer Sciences, 23, 2089-2106. doi:10.3906/elk-1305-41

18. Özdemir, A. T. and Danişman, K. (2011) Fully parallel ann-based arrhythmia classifier on a single-chip fpga: Fpaac,Turkish Journal of Electrical Engineering and Computer Sciences, 19(4), 667-687. doi:10.3906/elk-1006-488

19. Rangraz, P., Behnam, H., Shakhssalim, N. and Tavakkoli, J. (2012) A Feed-forward Neural Network Algorithm to Detect Thermal Lesions Induced by High Intensity Focused Ultrasound in Tissue, Journal of medical signals and sensors, 2(4),192-202.

20. Rao, S., Shrivastava, V., Dev, S. and Seetharamu, K. N. (2012) Prediction of the Damage Coefficient in a Prostate Cancer Tissue during Laser Ablation Using Artificial Neural Networks, Proceedings of the World Congress on Engineering,London, 3, 2-7.

21. Seera, M. and Lim, C. P. (2014) A hybrid intelligent system for medical data classification, Expert Systems with Applications, 41(5), 2239-2249. doi:10.1016/j.eswa.2013.09.022

22. Shukur, O. B. and Lee, M. H. (2015) Daily wind speed forecasting through hybrid KF-ANN model based on ARIMA, Renewable Energy, 76, 637-647. doi:10.1016/j.renene.2014.11.084

23. Søreide, K., Thorsen, K. and Søreide, J. A. (2014) Predicting outcomes in patients with perforated gastroduodenal ulcers: artificial neural network modelling indicates a highly complex disease, European Journal of Trauma and Emergency Surgery, 41(1), 91-98. doi:10.1007/s00068-014-0417-4

24. Su, B., Tang, J. and Liao, H. (2015). Automatic laser ablation control algorithm for an novel endoscopic laser ablation end effector for precision neurosurgery, IEEE International Conference on Intelligent Robots and Systems, Hamburg, 4362-4367. doi:10.1109/IROS.2015.7353996

25. Theisen-Kunde, D., Danicke, V. and Brinkmann, R. (2009) Comparison of two cw infrared laser systems emitting wavelengths at $1.92 \mu \mathrm{m}$ and $2.01 \mu \mathrm{m}$ for tissue dissection in liver surgery, IFMBE Proceedings, 25(6), 132-135. doi:10.1007/978-3-642-03906-5-36 
26. Tkáč, M. and Verner, R. (2015) Artificial neural networks in business: Two decades of research,Applied Soft Computing, 38,788-804. doi:10.1016/j.asoc.2015.09.040

27. Vogl, T.J., Mack, M. G., Straub, R., Eichler, K., Engelmann, K., Zangos, S. and Woitazek, D. (2001) MR guided laser-induced thermotherapy (LITT) of malignant liver and soft tissue tumours, Medical Laser Application, 16(2),91-102. doi:10.1078/1615-1615-00015

28. Vogl, T. J., Mack, M., Eichler, K., Lehnert, T. and Nabil, M. (2006) Effect of laser-induced thermotherapy on liver metastases, Expert review of anticancer therapy, 6(5), 769-774. doi:10.1586/14737140.6.5.769

29. Wang, C., Li, L., Wang, L., Ping, Z., Flory, M. T., Wang, G., Xi, Y. and Li, W. (2013) Evaluating the risk of type 2 diabetes mellitus using artificial neural network: An effective classification approach, Diabetes Research and Clinical Practice, 100(1), 111-118. doi:10.1016/j.diabres.2013.01.023

30. Wang, Y. C., Chan, T. C. and Sahakian, A. V. (2018) Real-time estimation of lesion depth and control of radiofrequency ablation within ex vivo animal tissues using a neural network, International journal of hyperthermia ,International Journal of Hyperthermia, 34(7),11041113. doi:10.1080/02656736.2017.

31. Yildiz, F. (2012). NIR-IR Lazerlerin Karaciğer Üzerindeki Etkilerinin In Vitro Ortamda Araştırılması ve Karşılaştırılması, Yüksek Lisans Tezi, İ.T.Ü. Fen Bilimleri Enstitüsü, İstanbul

32. Yildiz, F., Gulsoy, M. and Cilesiz, I. (2016) An experimental study on photothermal damage to tissue: The role of irradiance and wavelength, Laser Physics, 26(9), 95601. doi:10.1088/1054-660x/26/9/095601

33. Yildiz, F. and Özdemir, A. T. (2019) Prediction of laser-induced thermal damage with artificial neural networks,Laser Physics, 29(7), 075205. doi:10.1088/1555-6611/ab183b

34. Yucelbas, S., Ozsen, S., Yucelbas, C., Tezel, G., Kuccukturk, S. and Yosunkaya, S. (2016) Effect of EEG time domain features on the classification of sleep stages, Indian J. Sci. Technol, 9(25), 1-8. doi:10.17485/ijst/2016/v9i25/96630

35. Yücelbas, C., Yucelbas, S., Ozsen, S., Tezel, G., Kuccukturk, S. and Yosunkaya, S. (2016), Detection of sleep spindles in sleep EEG by using the PSD methods, Indian J. Sci. Technol., 9(25), 1-7. doi:10.17485/ijst/2016/v9i25/96628

36. Zhang, Y., Wu, L. and Wang, S. (2011) Magnetic Resonance Brain Image Classification By an Improved Artificial Bee Colony Algorithm, Progress In Electromagnetics Research, 116, 65-79. doi:10.2528/PIER11031709 
